\title{
Combination of Survival Analysis and Neural Networks to Relate Life Expectancy at Birth to Lifestyle, Environment, and Health Care Resources Indicators
}

\author{
Lazaros Iliadis and Kyriaki Kitikidou
}

Democritus University of Thrace,

Department of Forestry and Management of the Environment and Natural Resources,

Pandazidou 193, 68200, Orestiada, Greece

kkitikidafmenr.duth.gr

\begin{abstract}
This paper aims to shed light on the contribution of determinants to the health status of the population and to provide evidence on whether or not these determinants are producing similar results from two different statistical methods, across OECD countries. In this study, one output - Life Expectancy (LE) at birth of the total population - and three inputs are included. The inputs represent the three main dimensions of health outcome production: health resources (measured by health spending or the number of health practitioners), socioeconomic environment (pollution, education and income) and lifestyle (tobacco, alcohol and diet). A variable expressing country specificities is also used. Two independent statistical analyses, resulted that health resources and country specific effects are more closely related to LE.
\end{abstract}

Keywords: Artificial Neural Networks, Cox regression, Health status, Survival analysis.

\section{Introduction}

The health status of the population has many determinants. Lifestyle factors (tobacco, alcohol and diet) have numerous health effects. Excessive alcohol consumption increases the risk for heart stroke and vascular diseases, as well as liver cirrhosis and certain cancers. Alcohol consumption has fallen in many OECD countries since the early 1980 s but some countries are standing out; consumption has increased sharply in Ireland and has remained broadly stable in Nordic countries. The empirical results suggest that differences in alcohol consumption can help to explain a gap in Life Expectancy (LE) at birth of up to 1.8 years between low-consumption countries (such as Turkey) and high consumption ones (including France, Hungary and Ireland) [24]. Tobacco consumption is another important factor for health status. Influenced by public awareness campaigns, smoking prohibition in public areas and in the workplace, advertising bans and increased taxation, tobacco consumption has declined steadily in most OECD countries since the early 1980s, in particular in the United States, Canada and New Zealand where consumption has more than halved. However, disparities in tobacco consumption across countries remain large, with 
heavy smoking in the Czech Republic, Greece, Japan, the Netherlands and Turkey [24]. In addition to the lifestyle factors mentioned, a healthy diet is widely recognized as a major factor in the promotion and maintenance of good health. Low intake of fruits and vegetables is estimated by the World Health Organization (WHO) to be one of the main risk behaviors in developed countries. The consumption of fruits and vegetables has tended to increase over the past two decades in most OECD countries, with Japan and Switzerland being the main exceptions [24].

As regards socio-economic factors, the impact of pollution, education and income is increasingly recognized [17]. Per capita emissions of nitrogen oxide (NOx) have been widely used as a proxy for pollution. By contributing to the formation of fine particulate matter pollution, NOx emissions aggravate respiratory illness and cause premature death in the elderly and infants. They also play a major role in the formation of ground-level ozone (smog) pollution. On high ozone days, there is a marked increase in hospital admissions and visits for asthma and other respiratory illnesses. Since the early 1990s, however, NOx emissions per capita have declined in many OECD countries, partly reflecting technological improvements of combustion processes, in particular in power production and vehicle engines, and government plans aimed at reducing NOx emissions, e.g. Canada, European Union (World Health Report 2002). Although the strong relation between health and education is well established, the direction of causality is still debated and may well be both ways. Better health is associated with higher educational investment, since healthier individuals are able to devote more time and energy to learning. Because they live longer, they also have a greater incentive to learn since they have a higher return on human capital. On the other hand, education causes health if better-educated people use health care services more effectively; they tend to comply better with medical treatments, use more recent drugs and better understand discharge instructions. Education, as measured by the share of population aged 25 to 64 with an uppersecondary degree or higher, has been increasing steadily in particular in most of the countries with the lowest levels in the early 1980s (e.g. Belgium, Greece and Spain; Mexico, Portugal and Turkey being notable exceptions to this catch-up process) [17]. The level of income is even more correlated with the population health status across OECD countries than education. Higher GDP per capita affects health by facilitating access to many of the goods and services which contribute to improving health and longevity (e.g. food, housing, transportation). The relation between GDP per capita and health may also reflect working conditions - richer countries tend to have a higher share of service activities, which are considered to be less health damaging than others such as construction or industrial activities ([4]; [13]).

While recent studies invariably conclude that socio-economic and lifestyle factors are important determinants of the population health status, the contribution of health care resources has been much debated. Berger and Messer [1] as well as Or ([18];[19]) conclude that health care resources have played a positive and large role up to the early 1990s for a panel of OECD countries. Crémieux et al. [3] and Soares [22] reach similar conclusions for Canadian provinces and Brazilian municipalities, respectively. Hitiris and Posnet [8] and Nixon and Ulmann [15] both find that an increase in health expenditure per capita has an impact on health status, which is statistically significant but quite small. Likewise, Thornton [23] concludes for the United States that additional medical care utilization is relatively ineffective in lowering 
mortality and increasing life expectancy, and thus that health care policy which focuses primarily on the provision of medical services and ignores larger economic and social considerations may do little to benefit the nation's health. Finally, Filmer and Pritchett [5] as well as Self and Grabowski [21] find that health care resources have no significant impact on the population health status. Controversy about the link between health care resources and health status could reflect measurement problems and/or the fact that health-care resources represent too broad a concept, with some components having a more marked impact on health status than others.

The aim of this paper is to relate lifestyle factors, socioeconomic factors and health care resources to health status, using survival analysis (Cox regression) and Artificial Neural Networks (ANN). Similarity in the results from two different statistical analyses could lead us in a combination, for examining health data.

\section{Materials and Methods}

Regressions on a panel of 23 OECD countries over the period 1981-2003 have been used to assess the impact of health care resources on the health status of the population. This approach allows both changes over time in each country and differences across countries to be taken into account. Socio-economic and lifestyle factors affecting the population's health status, such as income and education, diet, pollution and consumption of alcohol and tobacco are examined [12].

The dependent variable is a measure of the population health status, alternatively:

LE at birth, for males and females,

LE at 65 , for males and females,

Premature mortality, for males and females,

Infant mortality.

Inputs consist of:

- $\quad$ spending $=$ health care resources per capita, either measured in monetary terms (total spending including long-term care at GDP PPP exchange rates and constant prices) or in hysical terms (e.g. health practitioners).

- $\quad$ tobacco = tobacco consumption in grams per capita.

- $\quad$ alcohol = alcohol consumption in liters per capita.

- $\quad \operatorname{diet}=$ consumption of fruits and vegetables per capita in kgs.

- pollution = emissions of nitrogen oxide $(\mathrm{NOx})$ per capita in kgs.

- $\quad$ education $=$ share of the population (aged 25 to 64$)$ with at least upper secondary education.

- $\quad \mathrm{GDP}=$ Gross Domestic Product per capita.

Panel data regression results suggested that health care resources, lifestyle and socioeconomic factors are all important determinants of the population health status. All regression coefficients for these inputs were highly statistically significant, and carried the expected sign, with health care resources measured either in physical or monetary terms. The choice of health status indicator (LE at birth, at older age, premature mortality, etc.) was not crucial to the analysis. Regression results provided estimates of the impact of the factors identified above on health status proxies, both over time and across 23 OECD countries 
In addition to the level of the exogenous variables described above, countries differ according to a number of characteristics which may also affect the health status of their population. Institutional features of their health system may play an important role. Failing to account for these country specificities would lead to biased estimates of the model coefficients. The introduction of country fixed-effects allows taking into account cross-country heterogeneity not reflected in other explanatory variables [12].

The analyses applied to these data were Cox regression ([9]; [14]; [16]) and Multiple Linear Perceptron (MLP) ANN. For the performance of the analyses, the SPSS v.19 statistical package was used ([10];[11]).

The Cox Regression procedure is useful for modelling the time to a specified event, based upon the values of given covariates. The basic model offered by the Cox Regression procedure is the proportional hazards model. The proportional hazards model assumes that the time to event and the covariates are related through the following equation.

$$
h_{i}(t)=\left[h_{0}(t)\right] e^{b_{0}+b_{1} x_{i 1}+\ldots+b_{p} x_{i p}}
$$

where

$\mathrm{h}_{i}(t)$ is the hazard rate for the $i$ th case at time $t$

$\mathrm{h}_{0}(t)$ is the baseline hazard at time $\mathrm{t}$

$p \quad$ is the number of covariates

$b_{j} \quad$ is the value of the $j$ th regression coefficient

$x_{i j} \quad$ is the value of the $i$ th case of the $j$ th covariate

The hazard function is a measure of the potential for the event to occur at a particular time $t$, given that the event did not yet occur. Larger values of the hazard function indicate greater potential for the event to occur.

The baseline hazard function measures this potential independently of the covariates. The shape of the hazard function over time is defined by the baseline hazard, for all cases. The covariates simply help to determine the overall magnitude of the function.

The value of the hazard is equal to the product of the baseline hazard and a covariate effect. While the baseline hazard is dependent upon time, the covariate effect is the same for all time points. Thus, the ratio of the hazards for any two cases at any time period is the ratio of their covariate effects. This is the proportional hazards assumption.

$$
S_{i}(t)=e^{-\int_{0}^{t}\left[h_{0}(t)\right] e^{b_{0}+b_{1} x_{i 1}+\ldots+b_{p} x_{i p}}}
$$

where $S_{i}(t)$ is the probability the $i$ th case survives past time $t$.

The concept of "hazard" may not be intuitive, but it is related to the survival function. The value of the survival function is the probability that the given event has not occurred by time $t$. Again, the baseline hazard determines the shape of the survival function.

In our study, we putted as dependent variable the LE at birth and spending, education, tobacco, alcohol, diet, pollution, GDP and country specific effect as covariates, and 
we applied the forward stepwise (Wald) algorithm. The status variable identifies whether the event has occurred for a given case. If the event has not occurred, the case is said to be censored. Censored cases are not used in the computation of the regression coefficients, but are used to compute the baseline hazard. In our study, the status variable is the country specific effect ( 1 if the effect is positive, 0 if the effect is negative).

For the performance of the ANN analysis, an MLP network model was used, applying the Back Propagation (BP) optimization algorithm. In BP the weighted sum of inputs and bias term are passed to the activation level through the transfer function to produce the output ([2]; [6]; [7]; [20]). The automatic architecture selection was used and the hyperbolic tangent function was applied. The architecture of the developed ANN included only one hidden layer, in an effort to keep the network as simple as possible.

Xiang et al. [25] report that neural network methods do not outperform Cox regression. Both methods have advantages and disadvantages; i.e. neural networks can detect complex patterns among the inputs, but they can be overlearned. On the other hand, in Cox regression, coefficients can be interpreted as the likelihood of an outcome given some value(s) of the risk factor, while neural networks weights usually do not lend themselves to such interpretation. Perhaps a combination of the two methods could give us interesting results.

\section{Results-Discussion}

In Cox regression, the model-building process took place in two blocks (Table 1). The omnibus tests are measures of how well the model performs. The chi-square change from previous step is the difference between the -2 log-likelihood of the model at the previous step and the current step. If the step adds a variable, the inclusion makes sense if the significance of the change is less than 0.05 . If the step removes a variable, the exclusion makes sense if the significance of the change is greater than 0.10 . In the first step, Country specific effect is added to the model. In the second step, spending is added to the model.

Table 1. Omnibus Tests of Model Coefficients

\begin{tabular}{cccccccccccc}
\hline & & \multicolumn{3}{c}{ Overall (score) } & \multicolumn{3}{c}{$\begin{array}{c}\text { Change From } \\
\text { Previous Step }\end{array}$} & \multicolumn{4}{c}{$\begin{array}{c}\text { Change From } \\
\text { Previous Block }\end{array}$} \\
\cline { 3 - 11 } & $\begin{array}{c}\mathbf{- 2} \text { Log } \\
\text { Step }\end{array}$ & $\begin{array}{c}\text { Likelihood } \\
\text { Square }\end{array}$ & df & Sig. & $\begin{array}{c}\text { Chi- } \\
\text { square }\end{array}$ & df & Sig. & $\begin{array}{c}\text { Chi- } \\
\text { square }\end{array}$ & df & Sig. \\
\hline $\mathbf{1}^{\mathbf{a}}$ & 17.498 & 6.296 & 1 & 0.012 & 6.865 & 1 & 0.009 & 6.865 & 1 & 0.009 \\
$\mathbf{2}^{\mathbf{b}}$ & 6.791 & 8.374 & 2 & 0.015 & 10.707 & 1 & 0.001 & 17.572 & 2 & 0.000 \\
\hline
\end{tabular}

a. Variable(s) Entered at Step Number 1: country specific effect

b. Variable(s) Entered at Step Number 2: spending

The $\operatorname{Exp}(\mathrm{B})$ in Table 2 can be interpreted as the predicted change in the hazard for a unit increase in the predictor. The value of $\operatorname{Exp}(\mathrm{B})$ for spending means that the hazard is reduced by $100 \%-(100 \% \times 0.00047)=99.95 \%$ for each monetary unit a 
country adds in health care resources. Likewise, the value of $\operatorname{Exp}(B)$ for Country_specific_effect is reduced by $100 \%-(100 \% \times 0.00458)=99.54 \%$ for each unit a country adds in its effects. Variables left out of the model have score statistics with significance values greater than 0.05 .

Table 2. Variables in the Cox regression model

\begin{tabular}{ccccccccccc}
\hline & & & & & & & \multicolumn{3}{c}{$\begin{array}{c}95,0 \% \text { CI for } \\
\text { Exp(B) }\end{array}$} \\
\hline Step 1 & $\begin{array}{l}\text { Country } \\
\text { Specific } \\
\text { Step2 }\end{array}$ & -1.077 & 0.485 & 4.932 & 1 & 0.026 & 0.34069 & 0.132 & 0.881 \\
& $\begin{array}{l}\text { - } \\
\text { Spenfect } \\
\text { Spending }\end{array}$ & -7.645 & 3.880 & 3.883 & 1 & 0.049 & 0.00047 & 0.000 & 0.960 \\
& $\begin{array}{l}\text { Country } \\
\text { specific } \\
\text { effect }\end{array}$ & -5.387 & 2.483 & 4.706 & 1 & 0.030 & 0.00458 & 0.000 & 0.595 \\
\hline
\end{tabular}

From the ANN analysis, 13 cases $(86.7 \%)$ were assigned to the training sample, and $2(13.3 \%)$ to the testing sample. The choice of the records was done randomly. Eight data records were excluded from the analysis because dependent variable values in the testing sample did not occur in the training sample. Nine units were chosen in the hidden layer.

Table 3 displays information about the results of training. Sum-of-squares error is displayed because the output layer has scale-dependent variables. This is the error function that the network tries to minimize during training. The relative error for each scale-dependent variable is the ratio of the sum-of-squares error for the dependent variable to the sum-of-squares error for the "null" model, in which the mean value of the dependent variable is used as the predicted value for each case.

The average overall relative errors are not constant across the training (0.025) and testing (1.173) samples. This could be due to limited data.

Table 3. ANN model summary

\begin{tabular}{rrl}
\hline Training & Sum of Squares Error & 0.149 \\
& Relative Error & 0.025 \\
& Stopping Rule Used & 1 consecutive step(s) with no decrease in error ${ }^{\mathrm{a}}$ \\
Training Time & $00: 00: 00.000$ \\
\hline Testing & Sum of Squares Error & 0.003 \\
& Relative Error & 1.173 \\
\hline
\end{tabular}

a. Error computations are based on the testing sample.

The importance of each independent variable (Table 4) shows that the variable that affects the most LE is country specific effect, followed by spending. 
Table 4. ANN independent variable importance

\begin{tabular}{rcc}
\hline & Importance & $\begin{array}{c}\text { Normalized } \\
\text { Importance }\end{array}$ \\
\hline Country_specific_effect & 0.249 & $100.0 \%$ \\
Spending & 0.167 & $66.9 \%$ \\
Pollution & 0.129 & $51.8 \%$ \\
Alcohol & 0.110 & $44.0 \%$ \\
Education & 0.107 & $43.0 \%$ \\
Diet & 0.089 & $35.7 \%$ \\
GDP & 0.075 & $29.9 \%$ \\
Tobacco & 0.074 & $29.6 \%$ \\
\hline
\end{tabular}

\section{Conclusions}

In this work, we have done an attempt to compare two completely different statistical analyses, in order to examine the similarity of the results. For this purpose, we used a health status variable as dependent (life expectancy at birth) and eight independent variables (spending, tobacco, alcohol, diet, pollution, education, GDP and country specificities), closely related to health status. Two analyses were applied: survival analysis (Cox regression) and Artificial Neural Networks (Multiple Linear Perceptron ANN). Results from both methods indicate that country specificities and health care resources (spending) are most important. Cox regression gives us a measure of hazard (health status decrease) for changes in the two independent variables, while MLP ANN classifies all independent variables, according to their importance. Combining the two methods could be useful and intriguing, for exploring and interpreting health data.

Aknowledgements. We wish to thank Mr James Kitchen, Marketing Manager of Public Affairs \& Communications Directorate of OECD, who gave us online access to the OECD publications.

\section{References}

1. Berger, M., Messer, J.: Public Financing of Health Expenditure, Insurance, and Health Outcomes. Applied Economics 34(17), 2105-2113 (2002)

2. Bishop, C.: Neural Networks for Pattern Recognition, 3rd edn. Oxford University Press, Oxford (1995)

3. Crémieux, P., Ouellette, P., Pilon, C.: Health Care Spending as Determinants of Health Outcomes. Health Economics 8, 627-639 (1999)

4. Cutler, D., Deaton, A., Lleras-Muney, A.: The Determinants of Mortality (2005), http: / / www.princeton.edu/ rpds / downloads / cutler_deaton_llera s-muney_determinants_mortality_nberdec05.pdf

5. Filmer, D., Pritchett, L.: Child Mortality and Public Spending on Health: How Much Does Money Matter? The World Bank (1997),

http: / / www . worldbank . org / html / dec / Publications /Workpapers /WP S1800series/wps1864/wps1864.pdf 
6. Fine, T.: Feedforward Neural Network Methodology, 3rd edn. Springer, New York (1999)

7. Haykin, S.: Neural Networks: A Comprehensive Foundation, 2nd edn. Macmillan College Publishing, New York (1998)

8. Hitiris, T., Posnett, J.: The Determinants and Effects of Health Expenditure in Developed Countries. Journal of Health Economics 11, 173-181 (1992)

9. Hosmer, D., Lemeshow, S.: Applied Survival Analysis. John Wiley and Sons, New York (1999)

10. IBM SPSS Complex Samples. SPSS Inc. (2010)

11. IBM SPSS Neural Networks 19. SPSS Inc. (2010)

12. Joumard, I., André, C., Nicq, C., Olivier, C.: Health Status Determinants: Lifestyle, Environment, Health Care Resources and Efficiency. OECD Economics Department Working Papers No. 627. OECD Publishing (2008)

13. Kiuila, O., Mieszkowski, P.: The Effects of Income, Education and Age on Health. Health Economics (2007),

http: / / www3.interscience.wiley.com/

cgi-bin/fulltext/114050615/PDFSTART

14. Kleinbaum, D.: Survival Analysis: A Self-Learning Text. Springer, New York (1996)

15. Nixon, J., Ullmann, P.: The Relationship between Health Care Expenditure and Health Outcomes - Evidence and Caveats for a Causal Link. European Journal of Health Economics 7(1), 7-19 (2006)

16. Norusis, M.: SPSS 13.0 Advanced Statistical Procedures Companion. Prentice Hall, Inc., Upper Saddle-River (2004)

17. OECD. OECD Environmental Outlook to 2030, Paris (2008)

18. Or, Z.: Determinants of Health Outcomes in Industrialised Countries: A Pooled, Crosscountry, Time Series Analysis. OECD Economic Studies (30), 2000/I (2000a)

19. Or, Z.: Exploring the Effects of Health Care on Mortality Across OECD Countries. OECD Labour Market and Social Policy, Occasional Paper No. 46 (2000b)

20. Ripley, B.: Pattern Recognition and Neural Networks. Cambridge University Press, Cambridge (1996)

21. Self, S., Grabowski, R.: How Effective is Public Health Expenditure in Improving Overall Health? A Cross-country Analysis. Applied Economics 35, 835-845 (2003)

22. Soares, R.: Health and the Evolution of Welfare across Brazilian Municipalities. Journal of Development Economics 84, 590-608 (2007)

23. Thornton, J.: Estimating a Health Production Function for the US: Some New Evidence. Applied Economics 34(1), 59-62 (2006)

24. World Health Report - Reducing Risks, Promoting Healthy Life. World Health Organization, France (2002)

25. Xiang, A., Lapuerta, P., Ryutov, A., Buckley, J., Stanley, S.: Comparison of the performance of neural network methods and Cox regression for censored survival data. Computational Statistics \& Data Analysis 34, 243-257 (2000) 